International Review of Research in Open and Distributed Learning Volume 22, Number 4

November - 2021

\title{
Editorial - Volume 22, Issue 4
}

Dietmar Kennepohl

Associate Editor, Athabasca University

Welcome to the last issue of the year. I would like to start with some good news. You should know that IRRODL has very recently been awarded the Directory of Open Access Journals (DOAJ) Seal. DOAJ is a community-curated online directory that indexes and provides access to high quality, open access, peerreviewed journals. Only around 10\% of journals indexed in DOAJ have been awarded the Seal. There are seven criteria which a journal must meet to be eligible for the DOAJ Seal. These relate to best practice in long term preservation, use of persistent identifiers, discoverability, reuse policies, and authors' rights. Those who already know IRRODL will find this as no surprise, but we think it is also nice to have the formal acknowledgement.

While we are recognizing milestones, I also wanted to alert you to a hidden gem written by David Lane and Claire Goode as a Technical Note entitled: Open for All: The OERu's Next Generation Digital Learning Ecosystem. It describes important work done by the OER Foundation to establish the infrastructure and "glue" for its resources and is the winner of the first OE Global Open Infrastructure Award. Congratulations!

Being aware of this one brilliant gem, I leave you now to unearth your own precious stones provided for you in this issue.

In our first paper, Munir, Anwar, and Kee examine the relationship between fear of COVID-19 and students' social presence in online learning reporting on and comparing the mediating role of student psychological motivation and cognitive problem-solving skills of students in Malaysia and Pakistan.

The community of inquiry (CoI) instrument was revisited by Yang and Su for construct revalidation by examining four competing models (unidimensional, correlated-factor, second-order factor, and bifactor) using confirmatory factor analysis. The study offers a more refined understanding of the underlying factors contained within the CoI instrument.

Nketekete and Mojalefa take a managerial perspective in their investigation of how open and distance learning (ODL) reform was directed at the National University of Lesotho. A critical analysis of policy and implementation, identifying short comings, is provided along with key actionable recommendations to mend and re-energize the current and future situation. This case study in the Lesotho context, provides valuable insight for those considering their own ODL change management.

In the search for solutions to the issues brought about by COVID-19 in education, the next article analyzes the affective fields that emerged from the discursive textual analysis of public-school students' survey responses in Brazil. The affective fields allowed authors Comelli, da Costa, and dos Santos Tavares to 
consider the friends-home-teachers tripod as fundamental to overcoming the phenomenon of affective fatigue that has been identified.

Xavier and Meneses explore the balance between student persistence and dropout that can come with increased flexibility. This case study draws on the knowledge of professors the Open University of Catalonia who are experienced e-learning designers for their own courses to pinpoint risks and opportunities that may enhance learning design and educational practices to foster student success.

Further on the theme of student persistence, Rudhumbu investigates determinants of students' behavioural intentions to continue with technology-mediated distance education in universities in Zimbabwe during COVID-19 and beyond. This quantitative study reveals factors significantly associated with the behavioural intentions to persist and has implications for both future policy and practice.

In the following study on institutional open educational resources (IOER) in Vietnam, Truong, Denison, and Stracke acknowledge the benefit high-quality educational materials at the lowest cost, but note it is complicated and limited by many contextual difficulties. This study found that IOER development is constrained by five categories of challenges, many of which are not identified in the literature.

Morgan, Childs, Hendricks, Harrison, DeVries, and Jhangiani collaboratively examine how five higher education institutions in Canada have progressed with their open education initiatives comparing the similarities and differences between their approaches and the evolution of their initiatives. The study employs an institutional self-assessment tool and how it is applied to open education practices at an institutional level is discussed.

Pulist then goes on to present us with an excellent book review of 25 Years of Ed Tech by Martin Weller (Athabasca University Press). The book provides not only a solid historical pedagogical perspective but some personal insight from Weller on the use of technology as a tool in the hands of educational practitioners.

In this Technical Note, Lane and Goode describe an OE Global award-winning comprehensive collection of open-source technologies (Next Generation Digital Learning Ecosystem) which have supported thousands of learners in the past year by providing infrastructure for accessing OERu consortium courses.

Finally, we are provided a Literature Review by Flavin and Bhandari analyzing 99 articles published on virtual learning environments (or learning management systems) in higher education in the years 20142018. The review describes the most frequent foci of research, as well as areas that have been underresearched in this five-year window.

\section{Athabasca University}

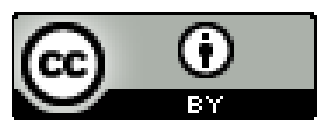

